\title{
System Integration of Large-Scale Wind Power in the Netherlands
}

\author{
B.C. Ummels, Member, IEEE, M. Gibescu, Member, IEEE, E. Pelgrum, W.L. Kling, Member, IEEE
}

\begin{abstract}
This paper presents the results of a simulation of system operation in the Netherlands in the presence of future large-scale wind energy production. The study is aimed at identifying bottlenecks in system planning and operation due to wind integration, in particular base-load and ramp rate problems. These may constraint the amount of wind that can be accommodated given a projected production park of dispatchable units and yearly load profile by 2012. Wind data from 20042005, interpolated to existing locations for onshore and planned locations for offshore wind parks, were used to create a realistic yearly wind energy output profile. The unit commitment and economic dispatch formulation includes ramp rate constraints for generation schedules and reserve activation as well as minimum up- and down times. Of particular interest in this study are the combined heat \& power (CHP) units, which impose additional constraints coupling their heat and energy production. Since no insight was available into the aggregated predictability of wind generation, both a 0 -MW prediction, where conventional units are scheduled to meet the total load, and a perfect prediction have been investigated. No forms of electrical or heat storage were considered. The results show no ramp rate problems in the Dutch system by 2012, however base-load problems may arise at high wind penetration levels, only to be prevented by wasting available wind resources.
\end{abstract}

\section{INTRODUCTION}

W IND power is becoming a generation technology of significance in a number of European countries, including the Netherlands. Due to the variability and unpredictability of wind, wind power production cannot be controlled to the same extent as conventional generation, and this complicates the task of power system balancing. To aid in the system integration of large-scale wind power, provision and management of reserve and regulating power must be investigated.

Besides employing storage and adjusting exchange schedules with neighboring systems, the use of conventional generation units to compensate for wind power variability and unpredictability is an obvious and often the only solution. The provision of system reserve for wind power is a wellresearched topic, usually focusing on sufficient generation capacity [1], [2]. Reference [3] focuses on reliability issues, rather than the technical capabilities of generating plants.

B.C. Ummels and M. Gibescu are with the Electrical Power Systems Group of Delft University of Technology, The Netherlands, e-mail: b.c.ummels@ewi.tudelft.nl

E. Pelgrum is with the Market and Regulation Department of TenneT bv, TSO of the Netherlands

W.L. Kling is with the Electrical Power Systems Groups of Delft University of Technology and Eindhoven University of Technology, the Netherlands and the Transmission Operations Department of TenneT bv, TSO of the Netherlands
Dany [4] investigates the impact of wind power on the required level of system reserves under central dispatch. However, a number of plant parameters critical to the unit commitment problem solution (minimum up- and down times, minimum production, etc.) are not specifically taken into account. In [5], a unit commitment program was adopted to determine the impact of wind power on the operation of a thermal system. Nevertheless, as this system is strongly interconnected, a large part of the regulating problems associated with wind power are effectively exported. Furthermore, operational requirements as defined by UCTE [6] are not considered.

This research focuses on investigating the technical capabilities of Dutch conventional generation for balancing wind power variability and unpredictability within the Dutch control area. The Dutch power system does not incorporate significant hydropower and has therefore no storage abilities. Moreover, slightly more than half of generation consists of combined heat and power units (CHP), which imposes additional constraints on the system commitment and dispatch. In addition, about $20 \%$ of generation is connected at the distribution level and hence not available for central dispatch. Our objective is to determine whether technical limitations to the amount of wind power that can be integrated within the Dutch system exist. It is assumed that power variations should be balanced within the control area in less than 15 minutes in order to bring back exchanges to their schedules, as required by UCTE. A scenario called 'Green Revolution', provided by the Dutch Transmission System Operator (TenneT) was used for the generation park make-up envisaged in 2012. This scenario is also used by TenneT for its transmission capacity planning [7]. The simulation method applied here uses a dynamic programming algorithm for solving unit commitment under ramp-rate constraints, such as described in [8].

As a first estimate of the problems to be encountered, duration curves for the net load (demand minus wind power) and aggregated variations of wind power and load have been developed (section II and III). Then, the technical capabilities of Dutch thermal generation units to mitigate these variations are discussed (section IV). Load data, wind power data and unit parameters were used as an input for the chronological simulation of unit-commitment with different wind power penetration levels. The study period is one year. The set-up for the simulations is discussed in section V. The results and the sensitivity of these results to the boundary conditions of the optimization problem are covered in sections VI and VII. Overall conclusions and an outline of future work conclude this paper (sections VIII and IX). 


\section{LOAD AND Wind POWER DURATION CURVES}

For a preliminary estimate of the impacts of large-scale wind power on power system balancing in the Dutch control zone, historical load data and wind power production estimates can be used to develop net load (electricity demand minus wind power) duration curves. Load duration curves show the number of hours in a year that the load level can be expected to be higher than a given value. Subtracting wind power (simply modelled as negative load) indicates the production range the conventional generation system must be able to satisfy. For the development of such a curve, load data and wind power data are needed on a common time basis.

The Dutch TSO, TenneT continuously monitors Dutch generation and international exchange. Market parties deliver their energy programs consisting of balanced generation, load and cross-border exchanges day-ahead to the TSO, on a $15 \mathrm{~min}$. time basis (program time unit, PTU). Dutch generation data are stored in a system-database, containing production schedules for all larger ( $>60 \mathrm{MW}$ ) units. Smaller, distributed generation units are not measured directly by TenneT, but their aggregated production can be obtained by subtracting generation data from load data and international exchanges, which are also monitored. For this research, system load data for the year 2003 for heat and power demand and imports were processed and extrapolated for the year 2012, using anticipated annual growth percentages of $2 \%$ per annum.

In the Dutch power system, about $1.2 \mathrm{GW}$ of onshore wind power has been installed so far, while $228 \mathrm{MW}$ of offshore wind power is presently under development. For the investigation of large-scale wind power, wind power production was modelled using weather data and wind turbine power curves. Wind speed data have been obtained from the Royal Dutch Meteorological Institute (KNMI) [9]. The data concerns 10minute wind speed averages with an accuracy of $0.1 \mathrm{~m} / \mathrm{s}$ for 18 locations in the Netherlands (9 onshore, 3 coastal, and 6 offshore) measured between May 31, 2004 and June 1, 2005. This historical wind speed data is used to estimate average daily wind patterns and to express the covariance between locations as a function of their distance. Then, for a new set of locations where wind parks are planned, wind time series for the study period are created such that the spatial correlation between the sites is taken into account. This is required because wind energy production units will be concentrated in areas with favorable wind conditions, hence their outputs may be strongly correlated. These cross-correlations are thus essential when evaluating system reserve and ramp rate requirements. For each of the projected locations, wind parks have been modelled using aggregated wind turbine power-speed curves to compute the power output for any given wind speed.

Figure 1 shows the result of an estimate of load-minus-wind power duration curve for the year 2012. The figure shows a load duration curve for 2012 as well as four load-minuswind power duration curves ( $2 \mathrm{GW}$ onshore and 0/2/4/6 GW offshore) based on one year of wind data. For 2012, energy consumption is calculated at $128 \mathrm{TWh}$ while maximum load

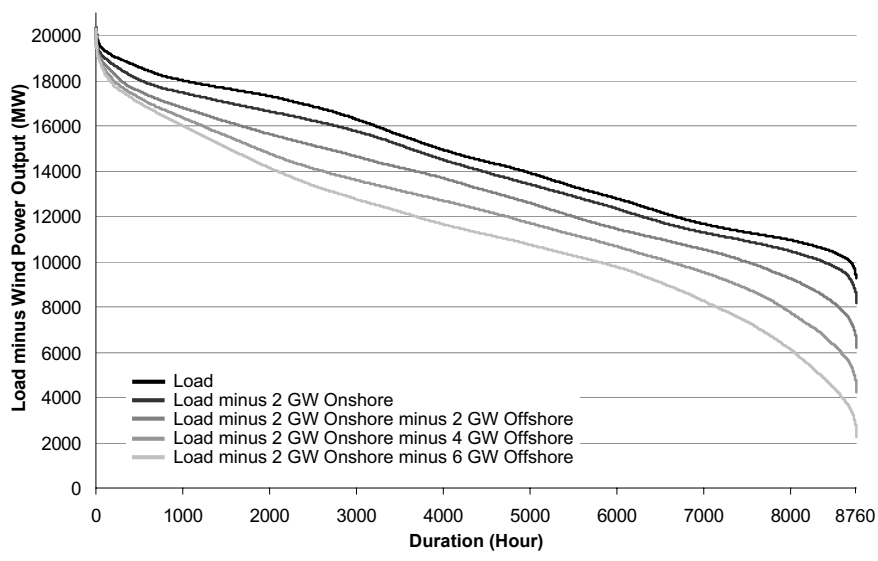

Fig. 1. Load duration curves with increasing wind power penetrations

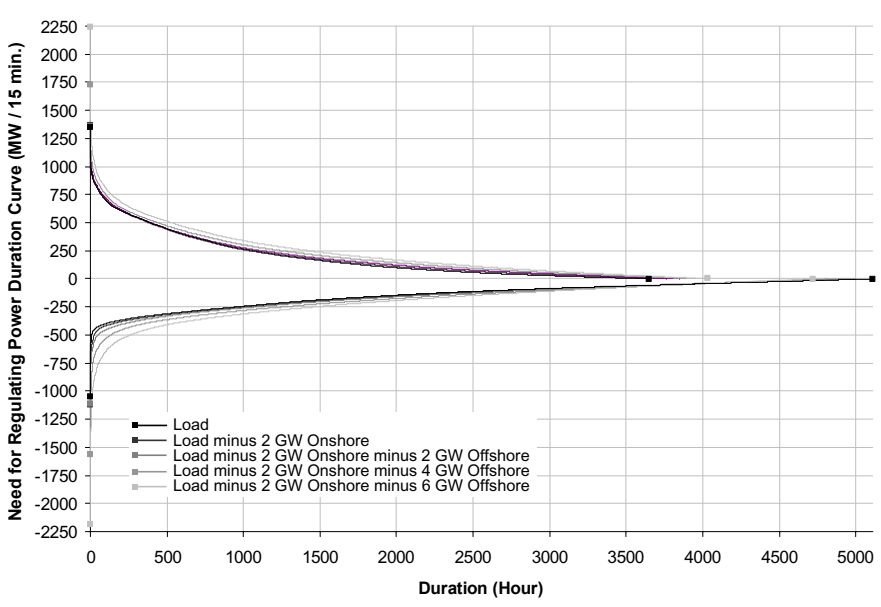

Fig. 2. Need for regulating power duration curve for power variations of load only (black line) and load and wind power combined (grey curves)

is estimated at $20,4 \mathrm{GW}$. Wind power capacity factors for this particular set of yearly wind data are $25 \%$ onshore and $46 \%$ offshore, respectively; obviously, these factors depend on the wind speed and will vary between years. Due to the small probability of the maximum load, the probability of maximum wind power at the same moment is slim, as a result of which the maximum of load-minus-wind power is negligibly lower than the maximum load. At the same time, lower loads occur more often, increasing the probability of wind power to be significant at these moments. The load-duration curve must be covered by imports and thermal generation output. From this curve it follows that the minimum load will decrease from about $9.5 \mathrm{GW}$ down to $2 \mathrm{GW}$ for an installed wind power capacity of $8 \mathrm{GW}$.

\section{LOAD AND WIND POWER VARIATIONS}

Variations in system load and wind power require a certain amount of regulating power (in this research, expressed in MW per 15 minutes). The total amount of regulating power required at any moment in time depends on the sum of variations in system load and wind power: wind power variations may counterbalance load variations and on the contrary. In order to determine the total amount of regulating power on the system scale, the aggregated variations must be investigated. This can 
be done by effectively regarding wind power as negative load.

In figure 2, the need for regulating power of load and increasing amounts of wind power are shown. Upward and downward regulating power are each arranged in decreasing order. From the figure, it can be concluded that with only load, downward regulating power is needed more often than upward regulating power (58\% versus $42 \%$ of time); consequently, upward regulating power exceeds downward regulating power in size (maxima of $+1351 \mathrm{MW} / 15 \mathrm{~min}$. and - $1048 \mathrm{MW} / 15$ min, respectively). This changes as the amount of installed wind power increases: for $8 \mathrm{GW}$ of installed wind power, downward regulating power is needed only $55 \%$ of time, thus lower then in the situation with only load variations. As can be expected, as the amount of wind power installed increases, both upward and downward regulating power increase in size (at $8 \mathrm{GW}$ wind power, +2243 and $-2190 \mathrm{MW} / 15 \mathrm{~min}$.).

For the incorporation of the unpredictability of wind power on a 15-minute basis, the simulation of wind power prediction errors is needed. Due to the lack of data available, a correct modelling of wind power prediction errors had to be left outside the scope of this research. Instead, a conventional approach of integrating wind power was assumed, namely a 0MW prediction at all times, resulting in an over-commitment of generation units. In order to determine the impact this assumption has on the simulation results, a $100 \%$ accurate prediction of wind power is taken into account as well. Including a $100 \%$ accurate prediction furthermore allows an estimate of the total technical space in the system for integrating wind power.

\section{THERMAL GENERATION UNITS}

In the Netherlands, significant hydro-power, which is commonly regarded as an ideal solution for balancing wind power variations, is absent. The capabilities of Dutch thermal generation plant are thus decisive for power system balancing. A large fraction of the central generation plant are gas-fired. Furthermore, a significant amount of distributed generation is present and a large portion of generation capacity supplies both power and heat. The TenneT scenario 'Green Revolution' provided by the Dutch TSO TenneT was used for the generation park envisaged in 2012. In table I, a general composition of the expected generation park in 2012 (excluding wind power) is given.

Important characteristics of these units, such as ramp rates and minimum up- and down-times, are available from an expert database. Before the liberalization of the Dutch electricity market in 1998, this database was used as an input for central unit commitment and dispatch by the system operator. From 1998 onwards, Dutch market parties are required to provide TenneT with a number of unit parameters [10]. The original database still contains a large amount of valid data, but a number of parameters or controls may have changed due to market operation. Therefore, a re-assessment of the capabilities of the generation units has been carried out, based on system observations and in-house experience at TenneT.
TABLE I

INSTALLED GENERATION IN 2012, EXCLUDING WIND POWER

\begin{tabular}{l||r|r}
\hline Generation Type & GW & $\%$ \\
\hline \hline Gas-Fired & 12.1 & $53 \%$ \\
Coal-Fired & 4.1 & $18 \%$ \\
Nuclear & 0.4 & $2 \%$ \\
Other & 9.5 & $4 \%$ \\
Distributed Generation & 5.2 & $23 \%$ \\
\hline Total Installed & 22.9 & \\
CHP of Total & & $55 \%$ \\
\hline
\end{tabular}

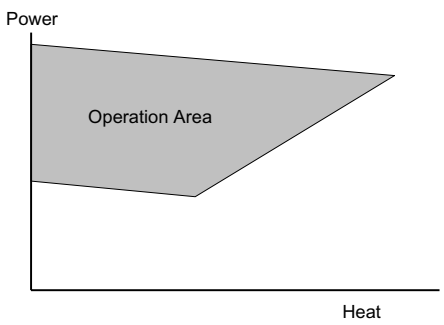

Fig. 3. Example of an operation area of a CHP-unit

\section{A. Combined Heat and Power Units}

An important portion of the Dutch generation units supplies both heat and power. As a result, each unit has certain operation constraints, defining the area (power $P$ and heat $H$ ) in which a CHP-unit can be operated. The operation area of each CHP-unit can be described as a set of $n$ linear inequality constraints of the type

$$
x_{i} P+y_{i} H \geq z_{i}
$$

for $i=1 \ldots n$ and has a general form as shown in 3. At high heat production, the flexibility of the unit decreases.

The total fuel cost for a CHP-unit is defined as the sum of a quadratic function of the electric power output, a quadratic function of the heat output, plus a crossover term linearly dependent on the product of the two:

$$
F(H, P)=f(1) H+f(2) P+f(3) P H
$$

The above cost function for each CHP is added to the total objective function to be minimized under the UTC problem formulation.

\section{B. Minimum Up- and Down Times}

The database contains data for all units regarding minimum up- and down times. Based on operation data and in-house experience, these times have been re-assessed. Specific attention has been given to the question, whether units are capable of operating in daily-cycles, requiring a minimum down-time of 8 hours or less. Since additional investments by market parties would be required to lower the minimum up- and down times of units, such shortened up/down times fall outside the scope of this research. 


\section{Ramp Rates}

The ramp rates of Dutch generation units have been estimated by examination of the operational requirements in force during the construction of most units [11], as well as the Dutch system code [10]. As the present operational requirements only specify a primary reaction, and not ramping capabilities, the ramp rates for new units are difficult to determine. At the same time, it is uncertain to what extent market parties are inclined to make full use of their unit capabilities [4]. Therefore, a rather conservative ramp rate of $1,5 \%$ of nominal output per minute has been assumed for most units; a small number of large coal units have been given a lower ramp rate. The ramp rate constraints are applied both inter-temporally, for changes in scheduled output between time intervals, and for reserve activation within a 15-minute interval.

\section{Heat Boilers}

Due to unit efficiency optima, the operation of CHP-units is most commonly heat driven. The presence of heat boilers adds extra flexibility to CHP-units: during low heat demand, heat boilers may take over the supply of heat in order to enable unit shutdown, while during high demand both the unit and the boiler will be in operation.is important for the flexibility of the unit when calculating unit commitment. In the system simulation, all existing heat boiler capacity was taken into account. For all new CHP-units in 2012, however, it has been assumed that these units have no heat boilers.

\section{Simulation Set-up}

In order to determine any technical limits to system balancing with large-scale wind power, some relevant aspects such as transmission constraints and the market design have been neglected. It is assumed, that the transmission system will be developed in such a way that wind power will not cause any extra congestion. Furthermore, central dispatch has been assumed in order to obtain the maximum technical space on a system level. In reality, wind power is integrated by market parties as wind power is subject to Program Responsibility [12]. As each market party is inclined to provide reserves for wind power individually, this may pose a non-technical limit to the integration of wind power, which has not been considered in this study. The simulations are based around a chronological unit-commitment model on a 15-minute time basis. For the simulation of all generation units, loads and wind power, the system simulation program PowrSym $3^{1}$ has been used.

\section{A. Unit Commitment Model}

The unit commitment tool incorporates dynamic programming to determine unit on/off status, combined heat and power optimization and a Monte Carlo forced outage model [13]. Three execution time horizons are used: an annual horizon for maintenance scheduling, a weekly horizon for production cost optimization and an hourly or other short time horizon for unit operation. The model uses heat demand for different

\footnotetext{
${ }^{1}$ PowrSym3 was developed by Operation Simulation Associates, Inc. and the former Netherlands Utility SEP, now TenneT bv.
}

TABLE II

Simulated Wind Power Penetrations

\begin{tabular}{l|l||l}
\hline $\begin{array}{l}\text { Onshore } \\
(\mathrm{MW})\end{array}$ & $\begin{array}{l}\text { Offshore } \\
(\mathrm{MW})\end{array}$ & $\begin{array}{l}\text { Total } \\
(\mathrm{MW})\end{array}$ \\
\hline \hline 0 & 0 & 0 \\
2 & 0 & 2 \\
2 & 1.25 & 3.25 \\
2 & 2 & 4 \\
2 & 3 & 5 \\
2 & 4 & 6 \\
2 & 6 & 8 \\
\hline
\end{tabular}

areas, system load, generation unit capabilities and wind power for different penetration levels (table II) as inputs.

For this research, the simulations have been set up to determine unit commitment and dispatch on a 15-minute basis (basic operational time step). Unit commitment and dispatch are optimized in order to achieve minimum operation cost, while all of the following constraints are met: 1) power demand 2) heat demand in all heat areas 3) commitment and dispatch within the capabilities of generation units. CHPunits are scheduled to meet a typical heat demand curve, depending on the type of heat load (district or industrial) for their associated areas and a part of system load at every time step, taking into account predicted wind power, power exchanges and a certain reserve margin at the system level. For the integration of wind power, the operation of heat boilers (enabling a shutdown of CHP-units and a consequent lower minimum load) is preferred to wasting available wind resources. Wasted wind is the ultimate option for integrating wind power in the Dutch system.

In the simulations, the following situations may occur, indicating possible technical limits for the integration of largescale wind power:

1) Insufficient downward regulating power: : This will result in an increase in the heat production by heat boilers (shutdown of CHP-units) and in wasting available wind resources

2) Insufficient upward regulating power: : This will result in energy not served (ENS) and indicates a 'hard' technical limit. From the analysis performed in section II and III, it can be concluded that upward and downward regulating power deficiencies will both occur in case regulating power presents a technical limit.

3) Minimum load problems: : This will result in an increase of heat production by heat boilers and in wasting available wind resources.

\section{B. System Reserves}

As this research has a focus on the technical capabilities of thermal generation plants, the possibility that market players may hold reserves on their own has not been taken into account in these simulations. Instead, the Dutch system has been assumed as one area under central dispatch, with the TSO as the sole reserve and regulation provider. Reserves are thus 


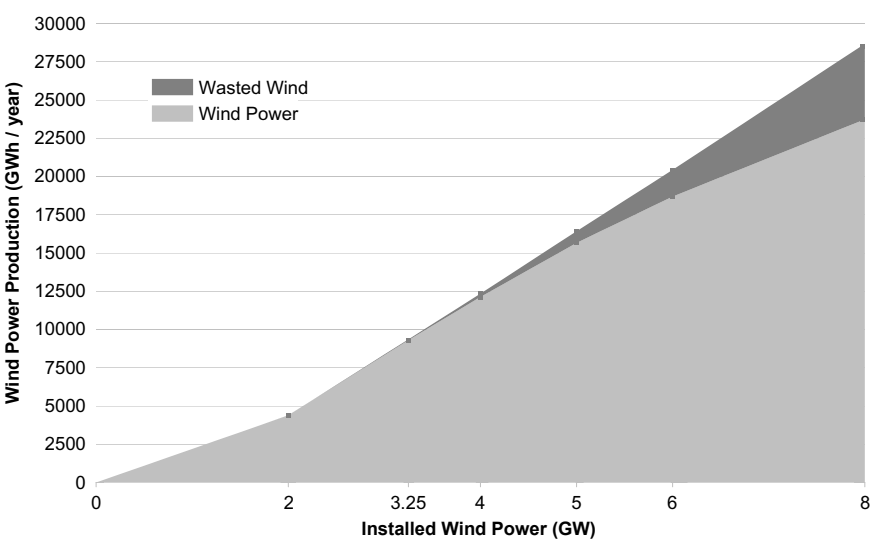

Fig. 4. Integrated wind power production and wasted wind for the simulated base-case: wind power prediction of $0 \mathrm{MW}$ and imports at the current level

held at the system level only. Imports have been assumed to be at the 2003 level, i.e. the level of imports is not influenced by wind power availability. Reserves are assumed to be the size of the largest outage at all times. Only spinning reserve, i.e. from units in operation (no fast start-up of other generation units) is considered in this study.

\section{Other Balancing Solutions}

Finally, it can be noted that only the technical capabilities of thermal generation units monitored by TenneT are assessed here. The output of distributed generation units is assumed to be $50 \%$ constant and $50 \%$ variable with system load and is thus independent of central unit commitment. As this research focuses on balancing wind power using Dutch thermal generation units only, the use of international trade has not been taken into account. Nor have other possible solutions for this, such as energy storage, and demand-side management.

\section{RESULTS}

\section{A. Wind Power Production and Wasted Wind}

The results of the simulations show that wind penetrations of about $4 \mathrm{GW}$ and above lead to minimum-load problems. At these moments, distributed generation, imports and generation by base-load thermal units cannot be decreased and threatens to exceed load minus wind power. As a result, wind power is regulated downwards and wind energy is increasingly wasted as installed wind power capacity increases (figure 4). The appearance of minimum load problems can be explained by the relatively large portion of units outside central dispatch (distributed generation, $25 \%$, table I) as well as the portion of units supplying both power and heat. Up to about $4 \mathrm{GW}$ installed wind power capacity, the amount of wasted wind is small. Nonetheless, it should be noted that minimum load problems do occur and and additional measures to avoid wasting wind would be required starting from $2 \mathrm{GW}$ and upwards. For all investigated wind power penetrations it is shown, that the combined variations of load and wind power can be taken care of by up/down regulation of thermal generation units.

In figure 5 , the relation between available wind power and wasted wind is shown on a weekly basis. The amount of wind
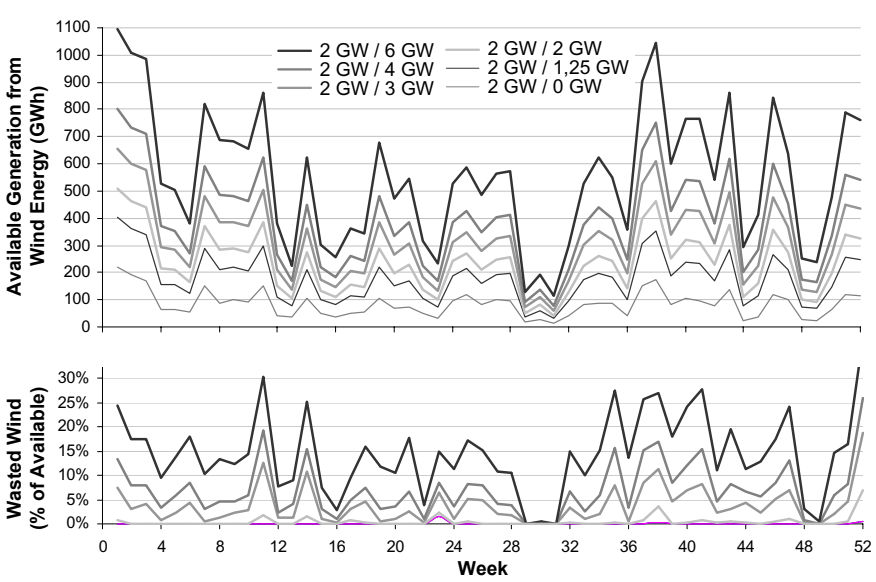

Fig. 5. Available generation from wind energy (GWh) and percentage of wasted wind per week at different wind power penetrations for the base-case

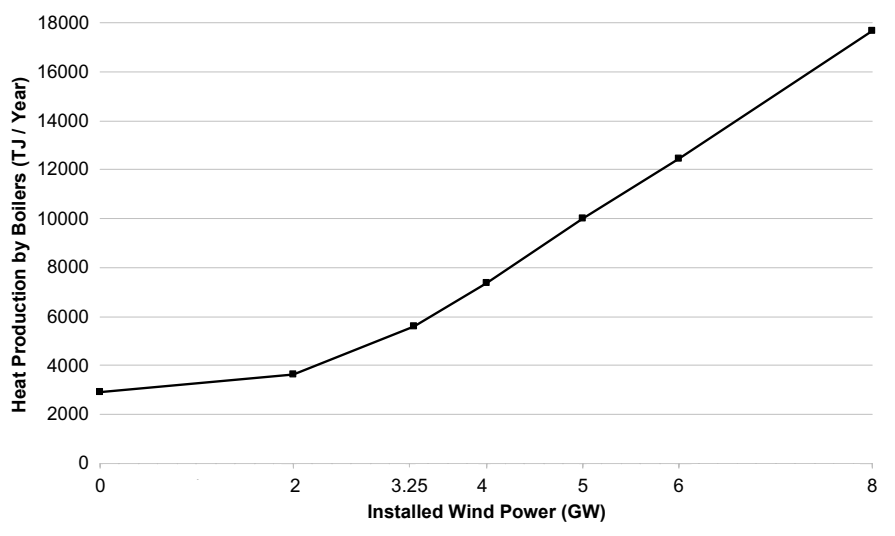

Fig. 6. Heat production by boilers for the base-case

power available significantly fluctuates between weeks and a clear relation exists between the availability of wind power and the amount of wasted wind per week. An exception to this rule is week 52, in which low load (holidays) results in a larger amount of wasted wind. From both figure 4 and 5 it follows that the total amount of wasted wind increases faster than linear with the increase in installed wind power capacity.

For all investigated wind power penetrations it is shown, that the combined variations of load and wind power can be taken care of by thermal generation units. However, increasing amounts of reserves are needed, resulting in a decrease in the possible emission- and fuel savings by use of wind energy. The absence of regulating problems can partly be explained by the points of departure used for the simulation. In case of a perfect prediction of wind power, sufficient units will be online for balancing the variations, whereas a 0 -prediction will result in an over-commitment of units at all times.

\section{B. Heat Boiler Production}

As figure 6 clearly shows, the amount of heat produced by heat boilers increases with the amount of installed wind power capacity. During hours of low load and high wind power, less need exists for production from other generation units: in some cases, CHP-units are shut down and heat boilers 


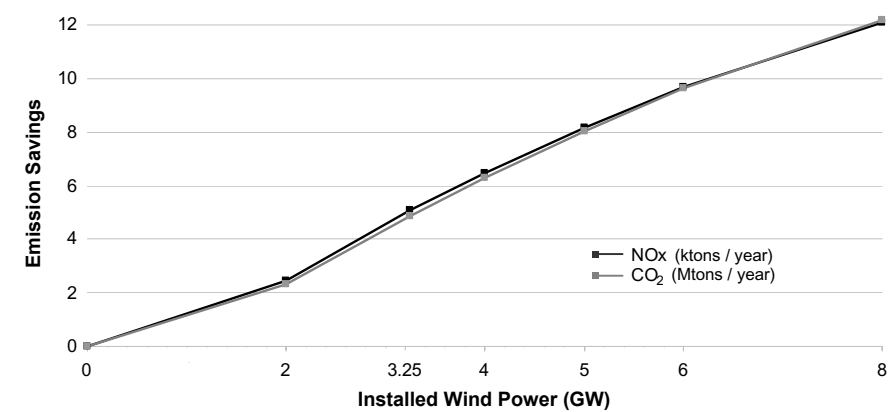

Fig. 7. $\mathrm{NO}_{x}$ and $\mathrm{CO}_{2}$ savings as a result of wind power

are used to cover heat demand in order to create additional space for regulating downwards. The increase in heat boiler production does not represent a 'hard' technical limit, but does involve additional costs associated with the integration of wind power. From the figure it can be concluded, that heat boiler production is six times larger at a wind power penetration of $8 \mathrm{GW}$ compared to no wind power installed.

\section{Emissions Savings}

The use of wind energy for power generation saves fossil fuel consumption of conventional power plant. At the same time, the amount of emissions decreases. In figure 7, an indication of the amount of exhaust gasses decline is given. Clearly, the emission and energy savings increase at a less steep slope past installed capacities of $4 \mathrm{GW}$ due to less efficient unit commitment and operation at high wind penetrations.

\section{Sensitivity ANALYsis}

Apart from the base-case, as defined in sections IV and V, a number of other cases have been simulated in order to determine the sensitivity of the results to certain assumptions. The following parameters have been investigated:

- Heat Boilers: The base-case assumed a conservative estimation of heat boiler capacities. In the modified analysis, it is assumed that new CHP-units have a full boiler backup instead of no heat boilers.

- Power Imports: In the base-case, imports are assumed to be at the 2003 level. In this new case, the simulations have been carried out without any imports.

The effects of heat boiler, power imports and the combination of these on the amount of wasted wind is shown in figure 8. The graph shows that, using less conservative assumptions for imports and boiler capacity, minimum load problems occur at higher wind power penetrations.

\section{A. Presence of Heat Boilers}

An increase in the presence of heat boilers creates additional flexibility for CHP-units and therefore additional possibilities to minimize thermal generation output. Would heat boilers be installed for all new CHP-units, the total amount of heat produced by boilers would increase significantly. Consequently, total energy savings increase as well due to a decrease in wasted wind, as back-up boilers would allow conventional unit shutdown at times of low load.

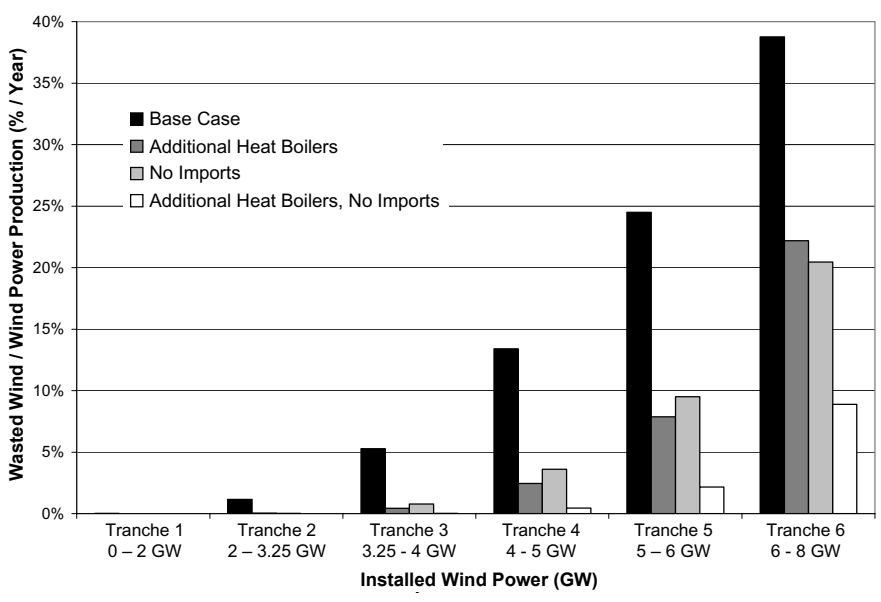

Fig. 8. Wasted wind as a percentage of total wind power production per tranche per year for the base-case and cases with additional heat boilers, no imports and both boilers and 0-imports

\section{B. Power Imports}

A reduction of power imports has a similar effect as adding heat boilers to the system. The realization of energy savings is however higher, because less CHP-units are being regulated downwards or shut down during high wind and low load conditions.

\section{CONCLUSIONS}

The research performed investigated the technical capabilities of thermal generation units to integrate wind power in the Dutch power system. A chronological unit-commitment model for both heat and power has been used to determine thermal unit operation schedules for increasing wind power penetrations. Conservative estimates have been used for the determination of technical capabilities of units (ramp-rates, heat boiler capacities). Based on the simulations and assumptions made for the base-case, it can be concluded that about $4 \mathrm{GW}$ of wind power can be technically integrated without significant additional measures. From $2 \mathrm{GW}$ installed wind power and upwards, minimum load problems require wasting some of the available wind resources. For all wind penetrations simulated here, regulating power deficiencies are not present; ramping up- and downwards are not a problem. In addition to technical feasibility, system operation with wind power has consequences for emission and fuel savings. The amount of wasted wind power at moments of high wind and low load show a large sensitivity to assumptions regarding import levels and the presence of heat boilers in the system. Finally, wind power prediction is found to have only a minor impact on power system balancing in the Dutch power system.

\section{FUTURE WORK}

The research method developed here and the unit-commitment model will be extended to include a number of aspects that have been deemed essential for future research.

The current Dutch market design, especially the system of Program Responsibility, influences the system integration of wind power in a number of ways. In the model under 
preparation, a number of generation-load balanced areas will be defined to include the behavior of different market parties. This way, the influence on market prices, international trade and management of reserves by individual market parties can be assessed. Transmission constraints between different areas can be defined so as to determine to what extent system congestions may occur.

From this research, it followed that wind power prediction has only a minor contribution in technically integrating wind power. Additional research is needed to determine the added value of wind power prediction to the efficient operation of conventional units. Also, the opportunities of wind power prediction for market parties individually can then be identified.

Future work will furthermore be performed to determine the possible benefits of other solutions than thermal generation management for wind power integration. Simulations will be performed to determine optimal technical solutions on a system scale. Solutions to be investigated include the use of energy storage facilities, international trade and demand-side management.

\section{ACKNOWLEDGEMENT}

This work is part of the project PhD@Sea, which is funded under the BSIK-program of the Dutch Government and supported by the consortium we@ sea, http://www.we-at-sea.org/. The authors acknowledge the use of system data and software provided by the Dutch TSO TenneT. Furthermore, the experience and support of the many people within TenneT who provided valuable input for this work are greatly acknowledged. Operation Simulation Associates is acknowledged for the licences for use of their unit commitment and dispatch software. The Royal Dutch Meteorological Institute (KNMI) is acknowledged for the use of wind speed data.

\section{REFERENCES}

[1] R. Billinton, G. Bai, "Generating Capacity Adequacy Associated with Wind Energy," IEEE Transactions on Power Systems, vol. 19, no. 3, pp. 641-646, 2004.

[2] L. Soder, "Reserve Margin Planning in a Wind-Hydro-Thermal Power System,” IEEE Transactions on Power Systems, vol. 8, no. 2, pp. 1345 1354, 1993.

[3] R. Doherty, M. O'Malley, "Quantifying reserve demands due to increasing wind power penetration." IEEE Bologna Power Tech Conference, 2003.

[4] G. Dany, "Kraftwerksreserve in elektrischen Verbundsystemen mit hohem Windenergieanteil," Ph.D. dissertation, 2000.

[5] H. Holttinen, J. Pedersen, "The Effect of Large-Scale Wind Power on a Thermal System Operation." 4th International Workshop on Large-Scale Integration of Wind Power and Transmission Networks for Offshore Wind Farms, Billund, DK, 2003.

[6] UCTE, "Policy 1: Load-Frequency Control and Performance," Tech. Rep., 2004.

[7] TenneT, “Capacity Plan 2006-2012," Tech. Rep., 2005.

[8] H. Wu, H.B. Gooi, "Optimal scheduling of spinning reserve with ramp constraints," IEEE Transactions on Power Systems, vol. 2, pp. 785 790, 1999

[9] KNMI, Royal Dutch Meteorological Institute, "Hydra Project." [Online]. Available: http://www.knmi.nl/samenw/hydra/index.html

[10] Dte, Dutch Office of Energy Regulation, Systeemcode (in Dutch), 2004.

[11] SEP, Cooperating Dutch Power Producers, "Uitvoeringsregeling ex artikel OVS ter nadere uitwerking van artikel 6, lid 1 OVS (bedrijfsvaardigheidsproeven) (in Dutch),' Tech. Rep., 13e uitgave, 1994.
[12] B.C. Ummels, M. Gibescu, W.L. Kling, G.C. Paap, "Power System Balancing with Offshore Wind Power in the Netherlands." Fifth International Workshop on Large-Scale Integration of Wind Power and Power Systems, 2005.

[13] Operation Simulation Associates, Inc., "Description of the PowrSym3 Computer Model," Tech. Rep., 1996.

\section{BIOGRAPHIES}

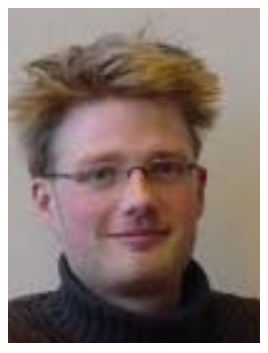

Bart C. Ummels received his M.Sc-degree in Systems Engineering, Policy and Management from Delft University of Technology in 2004. During his studies, he has done internships at Eltra, TSO of Western-Denmark and KEMA T\&D Consulting, the Netherlands. Currently he is working towards a Ph.D. at the Power Systems Laboratory of Delft University of Technology. His research interests include long term power system dynamics, large-scale wind power - power system interactions and power system operation in deregulated environments.

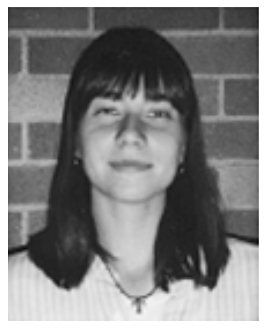

Madeleine Gibescu received her Dipl.Eng. in Power Engineering from the University Politehnica, Bucharest in 1993 and her MSEE and Ph.D. degrees from the University of Washington in 1995 and 2003, respectively. She has worked as a Research Engineer for Clearsight Systems, and as Power Systems Engineer for the AREVA T\&D Corp. of Bellevue, Washington. She is currently a postdoctoral researcher with the Power Systems Laboratory, Delft University of Technology. Her research interests include power system dynamics, power system security in an open access environment, and operations planning for systems with significant wind power.

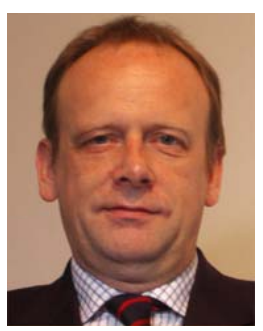

Engbert Pelgrum received his B.Sc. Degree in Electrical Engineering from the Technical College of Zwolle (the Netherlands). He is with the Market and Regulation department of TenneT bv, the Dutch Transmission System Operator. He is responsible for the development of European power market and transmission system simulation models, used in the field of system development and security of supply, as well as for analyses related to the medium and long term development of the Dutch and European power systems. He has over 20 years of experience in the area of chronological system modelling and power system operation and planning for the Dutch and foreign generation and transmission systems. 


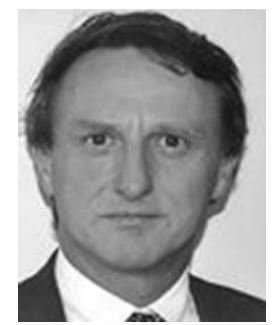

Wil L. Kling received his M.S-degree in electrical engineering from the Technical University of Eindhoven in 1978. Since 1993 he has been a (parttime) professor with the Department of Electrical Engineering at Delft University of Technology, in the field of Power Systems Engineering. In addition, he is with the Transmission Operations department of TenneT (the Dutch Transmission System Operator). Since 2000 , he has also been a part-time professor at the TU Eindhoven. His area of interest is related to planning and operations of power systems. Prof. Kling is involved in scientific organizations such as CIGRE and the IEEE. As Netherlands' representative, he is a member of the CIGRE Study Committee $\mathrm{C} 1$ on System Development and Economics, and a member of the Administrative Council of CIGRE. Furthermore, he is involved in several international working groups in the field of network planning and system studies, within UCTE, Eurelectric and other bodies. 